\title{
Acute superior mesenteric venous thrombosis with advanced gastric cancer: a case report
}

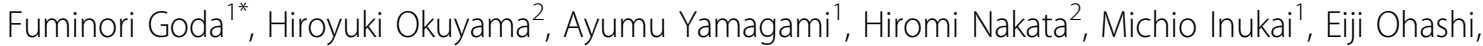 \\ Takeaki Kohno², Takashi Himoto², Hisashi Masugata², Shoichi Senda²
}

\begin{abstract}
Although the advanced stages of neoplasms have a risk of superior mesenteric venous thrombosis (MVT), an initial clinical diagnosis of MVT is sometimes difficult and it can be treated as a cancer-related pain using NSAIDs and/or opioids.

We herein present a case of palliative stage of cancer with acute MVT, which was successfully treated with immediate anticoagulant therapy. We believe this case provides an important clinical lesson, which is that we should remember that MVT is one of the potential causes of abdominal pain with cancer patients and the thrombosis can be easily identified by US and CT.
\end{abstract}

\section{Introduction}

Although the advanced stage of the neoplasm has a risk of superior mesenteric venous thrombosis (MVT) [1], an initial clinical diagnosis of MVT is sometimes difficult and it can be treated as a cancer-related pain. We herein present a case of palliative stage of cancer with acute MVT, which was successfully treated with immediate anticoagulant therapy. His clinical course suggests we should remember that MVT is one of the potential causes of abdominal pain with cancer patients and the thrombosis can be easily identified by US and $\mathrm{CT}$.

\section{Case presentation}

A 69-year-old male was admitted because of a continually worsening abdominal cramping pain, which had started two days before his admission. The pain was radiating to his back and it was associated with nausea and appetite loss. The patient had previously undergone a total gastrectomy for advanced gastric cancer two years earlier.

Thereafter, peritoneal relapse occurred and chemotherapy with paclitaxel and S-1 was administered by the outpatient department for six months with uneventfully. At admission, he was fully alert and his vital signs were

\footnotetext{
* Correspondence: fgoda@kms.ac.jp

'Cancer Center, Kagawa Medical University Hospital, 1750-1 Ikenobe, Miki-cho, Kita-gun, Kagawa, 761-0793, Japan
}

normal, although he had mild grade fever $\left(37.5^{\circ} \mathrm{C}\right)$. On examination, his abdomen was soft and flat with abdominal tenderness at the epigastrium, with diminished bowel sounds. Biochemical results and coagulation studies were within the normal limits. However, his symptoms were getting worse and opioid titillation was thus initiated. He underwent abdominal ultrasonography (US), which showed evidence of thrombosis or tumor thrombosis in the portal vein. A contrast-enhanced CT scan showed evidence of superior mesenteric venous thrombosis associated with thrombosis of the portal vein without cavernous formation(Figure 1). There was no thrombosis in the splenic vein (Figure 2). The dehydration was corrected by the fluid therapy. Anticoagulant therapy was started, because the thrombosis had formed recently and the risk of bleeding was low. The patient was given lowmolecular-weight heparin (Dalteparin sodium, Fragmin) at a dosage of 10,000 $\mathrm{U}$ per day. Three days after the administration of heparin, he had a complete recovery from abdominal pain without opioid use and was thus able to start eating. He was discharged after 14 days of admission with a shift of the anticoagulant therapy to warfarin with a targeted international normalized ratio (PT-INR) of 1.5-2.0. Three months later, he was doing well and the thrombosis of the superior mesenteric vein and portal vein had completely disappeared on a followup CT. Six months later, he died from gastric cancer and the autopsy showed no thrombosis in the superior mesenteric vein and portal vein. 


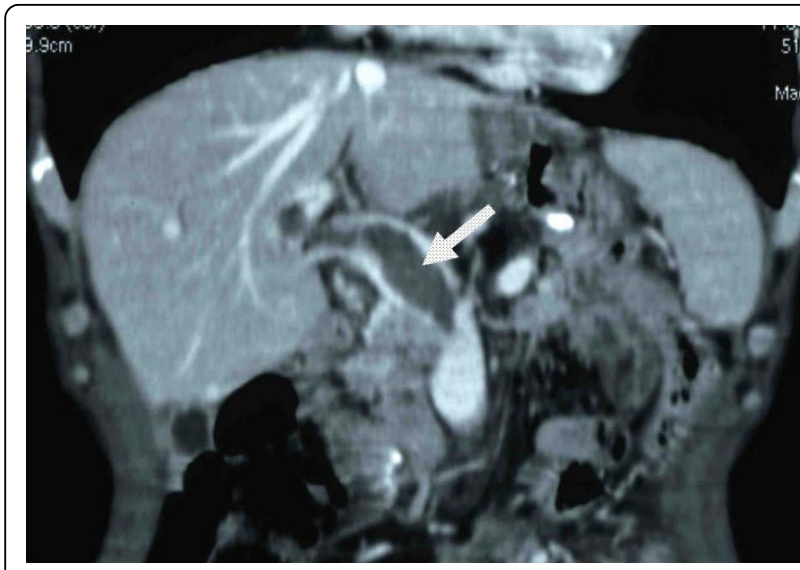

Figure 1 Contrast-enhanced abdominal CT. The thrombosis located in the superior mesenteric vein with portal vein (arrow) without cavernous formation.

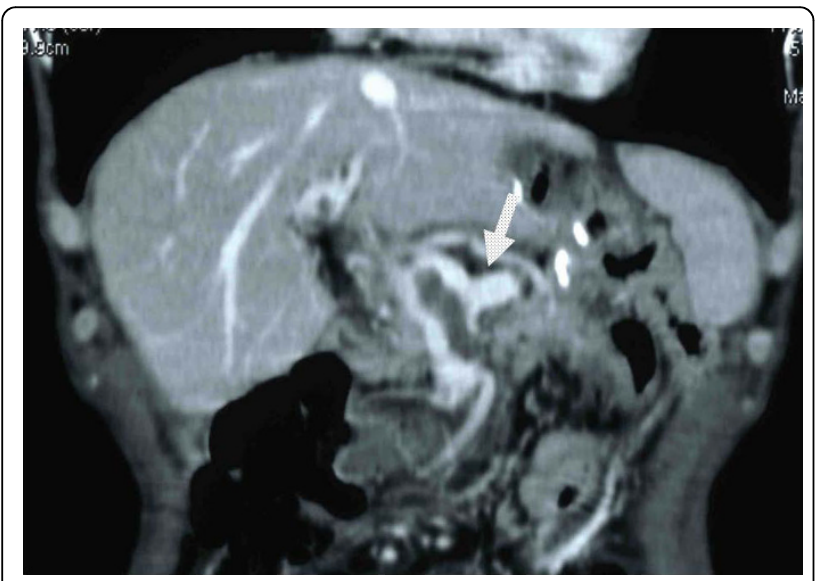

Figure 2 Contrast-enhanced abdominal CT. No thrombosis was observed in the splenic vein (arrow).

\section{Discussion}

MVT has been assumed to be a very rare disease. The incidence of MVT was estimated at 1.8-2.7 per 100000 person-years[2,3]. This accounts for $1.5-6.2 \%$ of patients of acute mesenteric ischemia in various studies[4]. The neoplasm is among the more common causes of mesenteric venous thrombosis. As illustrated in Table 1, 83 (21\%) of 395 cases of MVT associated with neoplasm [2-7]. The advanced stage of the neoplasm has a risk of developing MVT such as, hyper-coagulability, a low flow state in the superior mesenteric vein as a result of dehydration and chemotherapy $[5,8,9]$.

The clinical diagnosis of MVT associated with a neoplasm is sometimes difficult. The symptoms and signs of MVT are non-specific, such as abdominal pain with nausea, vomiting, diarrhea/constipation and fever [4], and the initial physical findings may often appear to be
Table 1 Incidence of Cancer relative MVT

\begin{tabular}{lccc}
\hline \multicolumn{1}{c}{ Authors } & term & cases & cancer related cases \\
\hline Acosta, S(2005) [2] & $1970-1982$ & 23 & $8(35 \%)$ \\
\hline Acosta, S(2008) [3] & $2000-2006$ & 51 & $12(24 \%)$ \\
\hline Kumar, S(2003) [4] & $1979-1998$ & 69 & $9(13 \%)$ \\
\hline Janssen, HL(2001)[5] & $1984-1997$ & 172 & $41(24 \%)$ \\
\hline Sogaard K(2001)[6] & $1992-2005$ & 67 & $9(13 \%)$ \\
\hline Morasch, MD(2001)[7] & $1985-1999$ & 13 & $4(31 \%)$ \\
\hline total & & 395 & $83(21 \%)$ \\
\hline
\end{tabular}

entirely normal. These conditions are often assumed to be cancer related symptoms, which can be treated with NSAIDs and/or opioids. In the present case, the initial diagnosis was cancer-related pain during chemotherapy for gastric cancer with peritonitis carcinomatosa.

The use of advanced imaging techniques provided useful and helpful information. US is a powerful modality for the screening of a suspected thrombosis. Contrast-enhanced CT, which facilitates the early and accurate detection of thrombosis, including fresh thrombosis with a high sensitivity [4], therefore indicated the precise location of the thrombosis and the duration of the thrombosis in this case.

The best strategy for MVT is its early diagnosis and immediate treatment [1]. Anticoagulant therapy, which generally allows for the re-canalization of the thrombosed vein in recently formed thromboses, is recommended in patients with acute MVT to improve the survival without increasing the risk of bleeding $[4,10]$, however, reliable data for the palliative stage of cancer patients with MVT is still scarce.

\section{Conclusion}

The palliative stage of a cancer patient with MVT was successfully treated. It is important to remember that MVT is one of the causes of abdominal pain in cancer patients and such thrombosis can be easily identified by both US and CT. Even in palliative stage cancer patients, the immediate use of anticoagulants can improve both the QOL and the prognosis of the patients.

\section{Consent}

Written informed consent was obtained from the patient for publication of this case report and accompanying images. A copy of the written consent is available for review by the Editor-in-Chief of this journal.

\section{Author details}

${ }^{1}$ Cancer Center, Kagawa Medical University Hospital, 1750-1 Ikenobe, Miki-cho, Kita-gun, Kagawa, 761-0793, Japan. ²Department of Integrated Medicine, Kagawa Medical University Hospital, 1750-1 Ikenobe, Miki-cho, Kitagun, Kagawa, 761-0793, Japan. 


\section{Authors' contributions}

FG managed the case with full responsibility, and wrote manuscript. HO, AY, TK, TH, HM treated the patient and interpreted the patient data. HN, MI, EO contributed to the writing and editing of the manuscript. SS was the general consultant and advised in the management of the case and writing of the manuscript. All the authors read and approved the final manuscript.

\section{Competing interests}

The authors declare that they have no competing interests.

Received: 6 January 2009 Accepted: 9 March 2010

Published: 9 March 2010

\section{References}

1. Kumar S, Sarr MG, Kamath PS: Mesenteric venous thrombosis. N Engl J Med 2001, 345:1683-8.

2. Acosta S, Ogren M, Sternby NH, Bergqvist D, Bjorck M: Mesenteric venous thrombosis with transmural intestinal infarction: a population-based study. J Vasc Surg 2005, 41:1683-8.

3. Acosta S, Alhadad A, Svensson P, Ekberg O: Epidemiology, risk and prognostic factors in mesenteric venous thrombosis. $\mathrm{Br}$ I Surg 2008 95:1245-51.

4. Kumar S, Kamath PS: Acute superior mesenteric venous thrombosis: one disease or two?. Am J Gastroenterol 2003, 98:1299-304.

5. Janssen HL, Wijnhoud A, Haagsma EB, van Uum SH, van Nieuwkerk CM, Adang RP, Chamuleau RA, van Hattum J, Vleggaar FP, Hansen BE, Rosendaal FR, van Hoek B: Extrahepatic portal vein thrombosis: aetiology and determinants of survival. Gut 2001, 49:720-4.

6. Sogaard KK, Astrup LB, Vilstrup H, Gronbaek H: Portal vein thrombosis; risk factors, clinical presentation and treatment. BMC Gastroenterol 2007, 7:34.

7. Morasch MD, Ebaugh JL, Chiou AC, Matsumura JS, Pearce WH, Yao JS: Mesenteric venous thrombosis: a changing clinical entity. J Vasc Surg 2001, 34:680-4.

8. Brisse H, Orbach D, Lassau N, Servois V, Doz F, Debray D, Helfre $S$, Hartmann $\mathrm{O}$, Neuenschwander S: Portal vein thrombosis during antineoplastic chemotherapy in children: report of five cases and review of the literature. Eur J Cancer 2004, 40:2659-66.

9. Feenstra J, Vermeer RJ, Stricker BH: Mesenteric venous thrombosis attributed to docetaxel. Am J Clin Oncol 2000, 23:353-4.

10. Spanier BW, Frederiks J: Aetiology of extrahepatic portal vein thrombosis. Gut 2002, 51:755-6.

doi:10.1186/1757-1626-3-76

Cite this article as: Goda et al.: Acute superior mesenteric venous thrombosis with advanced gastric cancer: a case report. Cases Journal 2010 3:76.

\section{Submit your next manuscript to BioMed Central and take full advantage of:}

- Convenient online submission

- Thorough peer review

- No space constraints or color figure charges

- Immediate publication on acceptance

- Inclusion in PubMed, CAS, Scopus and Google Scholar

- Research which is freely available for redistribution 